\title{
Increase of Lactoferrin Concentration in Mastitic Goat Milk
}

\author{
Po-Wen $\mathrm{CHEN}^{1)}$, Wen-Cheu $\mathrm{CHEN}^{1)}$ and Frank Chinhung $\mathrm{MAO}^{1) *}$ \\ ${ }^{1)}$ Department of Veterinary Medicine, National Chung-Hsing University, Taiwan
}

(Received 3 June 2003/Accepted 11 November 2003)

ABSTRACT. Lactoferrin concentration (LFC) in normal and mastitic milk of dairy goats were examined. LFC in bulk milk collected from 70 dairy goat farms and individual milk samples from 10 goats with mastitis were measured by enzyme-linked immunosorbent assay (ELISA) and their reaction time in methylene blue reduction test (MBRT) monitored. Bulk milk samples were categorized into three grades, such as high, normal and low, based on the reaction time in MBRT. The mean LFC in milk that was considered high quality $(167 \mu \mathrm{g} / \mathrm{m} l)$ was significantly lower than that of those graded as normal $(218 \mu \mathrm{g} / \mathrm{m} l)$ and low quality $(304 \mu \mathrm{g} / \mathrm{m} l)$, while mean LFC in mastitic milk was $587 \mu \mathrm{g} / \mathrm{m} l$. The correlation coefficient between milk LFC and MBRT time was found to be -0.7 . Three goats were inoculated with Staphylococcus aureus into one of their udder halves. The mean milk LFC was found to be significantly higher (1500 $\mu \mathrm{g} / \mathrm{m} l)$ than the control $(30 \mu \mathrm{g} / \mathrm{m} l)$. These findings suggest that milk LFC may be useful as an index for intramammary infection in goats. KEY WORDS: goat, lactoferrin, mastitis, methylene blue reduction test, milk.

Lactoferrins are glycoproteins found in many external secretions of mammals [22]. They are especially abundant in milk and in azurophile granules of neutrophils [4, 34]. They have been associated with a variety of biological functions that include inhibition of a number of microorganisms, transport of iron, immune modulation, enhancing cell differentiation and regulation of several other cell functions [3, $17,31,33]$. Thus, it is very important to monitor the changes of lactoferrin levels in biological fluids to detect any physiological changes or infection in mammals. Masson et al. [23] reported that neutrophils can release lactoferrin to enhance the local concentration of the protein during inflammation. Hansen et al. [13] measured the plasma lactoferrin concentration by radioimmunoassay and compared it to the neutrophils kinetics. A lactoferrin latex agglutination test has been used to screen for inflammatory genital infections in women [25]. Moreover, lactoferrin concentration in several kinds of specimens or body fluids such as the semen or the breast milk has also been determined by the electrophoresis and an enzyme-linked immunosorbent assay (ELISA), respectively [2, 30].

Lactoferrin concentration (LFC) in human, cow and sow milk has been reported $[11,16,19]$ but information on LFC in goat milk is scarce. Masson and Heremans [22] have reported the LFC in milk from guinea pig, cow, goat, mare and mouse by the radial immunodiffusion method. However, the sample size used in their study was not considered sufficient. In this study, we developed an ELISA for evaluating the LFC in goat milk from large herds in relation to their infection status.

\section{MATERIALS AND METHODS}

Milk samples: Milk samples from normal lactating and

\footnotetext{
* Correspondence to: Mao, F.C., Department of Veterinary Medicine, National Chung-Hsing University, 250 Kuo Kuang Rd., Taichung, Taiwan.
}

mastitis goats were collected from the bulk milk of 70 different commercial goat farms in Southern Taiwan from October 2002 to January 2003. The bulk milk, which does not contain any colostrum, was composed of milk from individual goats at different lactational period. Each farm had more than 200 heads of dairy goats consisting of various pure breeds of Saanen, Alpine, Nubian or Toggenburg as well as various unidentified cross-breeds. Moreover, ten individual milk samples in one farm were collected from the goats with mastitis that persisted for more than 20 days. Whenever clinical mastitis was found in any of the dairy goats, the milk from those goats was discarded. Therefore, only individual mastitic milk was collected for the experiment. All the milk samples, which were stored and transported at $4{ }^{\circ} \mathrm{C}$, were subjected to LFC measurement and the methylene blue reduction test (MBRT) immediately after the sample arrival at our laboratory.

Intramammary infection with Staphylococcus aureus: Three goats (2 Alpine and 1 Saanen breed) were used in this test. The conduct of animal experiment followed the principles of Animal Protection Law in Taiwan (Promulgated on November 4, 1998). The goats were housed individually in a sheltered concrete pen and reared under intensive husbandry condition. Moreover, the goats were milked by hand twice daily, once in the morning and evening. They were fed a lactation diet twice daily. The animals were determined to be healthy by clinical examination during the experiment, and were treated for their mammary infection at the end of the experiment.

Milk samples were collected from all udder halves before intramammary inoculation with bacteria $(0 \mathrm{hr})$. One hr after the first collection of the milk samples, one of the udder halves of each goat was inoculated with $100 \mathrm{CFU}$ (colony formation unit) per $\mathrm{m} l$ of Staphylococcus aureus (ATCC $31885)$ [1,32], and the other udder half was left untreated to serve as control. Milk samples from each udder half were subsequently collected at 24, 48 and $72 \mathrm{hr}$ after inoculation. 
The LFC measurement and somatic cell count (SCC) (Bentley SCC 300, U.S.A.) of the collected samples were carried out. Bacteriological examination was also performed to monitor the infection status inside the udder-halves during the experiment.

Isolation of goat lactoferrin: Goat lactoferrin was purified from colostrum as described in the previous study [24]. The purity of the lactoferrin obtained was assessed by SDSPAGE and Western blotting. The purified goat lactoferrin was used as standard and conjugated with biotin for use in competitive lactoferrin ELISA assay.

Caprine lactoferrin ELISA: Competitive ELISA was carried out with reference to the previously reported $\beta$-lactoglobulin ELISA [21]. Briefly, lactoferrin antiserum was obtained by immunizing three rabbits with bovine lactoferrin (Sigma, U.S.A.) according to the recommendation of the manual written by Harlow and Lane [14]. The antiserum was diluted 30,000 fold with coating buffer and then coated onto an ELISA microplate (Nunc, U.S.A.). The purified goat lactoferrin was conjugated with NHS-LC-Biotin (1:5) (Pierce, U.S.A.) according to the instruction in the manual. The prepared lactoferrin-LC-biotin was diluted 250,000 fold in assay buffer to be used for the competition reaction. ExtrAvidin-peroxidase (Sigma, U.S.A.) was diluted 10,000 fold in assay buffer to give an optimal color development.

Methylene blue reduction test (MBRT): The MBRT which was performed according to the standard method [26].

Milk fat, acidity and specific gravity: The bulk milk samples were analyzed for their milk fat, titratable acidity and specific gravity according to the standard methods described in Chinese National Standard [5].

Statistical analysis: All the statistical analyses were performed using SAS [27]. Comparisons involving more than two milk groups for the mean values of milk LFC, fat, acidity or specific gravity in low, normal or high quality milk were analyzed by one-way ANOVA using Duncan's multiple range analysis. The relationship between milk LFC and MBRT reaction time were analyzed by Pearson's correlation test. For the challenged goats, the mean LFC or SCC in S. aureus-inoculated milk samples collected at 24,48 or 72 hr were compared to that collected at the $0 \mathrm{hr}$ (control milk;

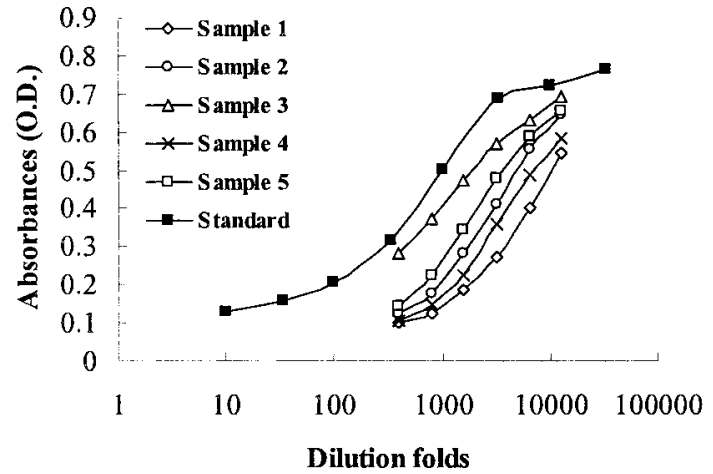

Fig. 1. The ELISA parallelism test for goat lactoferrin standard and 5 serially diluted milk samples.

before inoculation of $S$. aureus) by student's $t$ test. In all statistical comparisons, a $P$ value less than 0.05 was considered as showing significant difference.

\section{RESULTS}

Parallelism test in LFC ELISA system: Figure 1 shows the results of parallelism test for the lactoferrin standard and five serially diluted milk samples. The light absorptions for the serially diluted milk samples were almost parallel to that of the standard curve between points at 800 to 3200 dilutions. This implies that our ELISA is suitable for detecting lactoferrin in milk samples.

LFC in bulk and mastitic milk: The LFC of the bulk or mastitic milk are shown in Table 1 . The quality of the goat milk was categorized as high, normal and low according to the results obtained in MBRT. This is one of the standard practices for setting the price of milk in Taiwan. When the MBRT time for a certain sample of bulk milk is more than 8 $\mathrm{hr}$, it is considered as high quality milk, but when it is less than $5 \mathrm{hr}$, the milk will not be accepted for sale. The mean LFCs of high, normal and low quality milk were found to be 167, 218 and $304 \mu \mathrm{g} / \mathrm{m} l$, respectively (Table 1). The 95\% confidence (mean \pm 2 standard deviation) for milk LFC in high quality milk ranged from 69 to $265 \mu \mathrm{g} / \mathrm{m} l$. In addition,

Table 1. Lactoferrin concentration, fat, acidity and specific gravity of each milk samples (Mean \pm Standard deviation)

\begin{tabular}{lcccccc}
\hline & & \multicolumn{4}{c}{ Mean } \\
\cline { 3 - 7 } Milk quality $^{\mathrm{a})}$ & MBRT (hr) & Number $^{\mathrm{b})}$ & $\begin{array}{c}\text { Lactoferrin } \\
(\mu \mathrm{g} / \mathrm{m} l)\end{array}$ & $\begin{array}{c}\text { Fat } \\
(\%)\end{array}$ & $\begin{array}{c}\text { Acidity } \\
(\%)\end{array}$ & $\begin{array}{c}\text { Specific } \\
\text { Gravity }\end{array}$ \\
\hline High & $\geq 8$ & 54 & $167 \pm 49^{\mathrm{d})}$ & $3.8 \pm 0.37$ & $0.148 \pm 0.01$ & $1.031 \pm 0.001$ \\
Normal & $\geq 5$ and $<8$ & 47 & $\left.218 \pm 77^{\mathrm{e}}\right)$ & $3.91 \pm 0.37$ & $0.158 \pm 0.03$ & $1.031 \pm 0.001$ \\
Low & $<5$ & 5 & $\left.304 \pm 87^{\mathrm{e}}\right)$ & $3.64 \pm 0.15$ & $0.148 \pm 0.01$ & $1.031 \pm 0.001$ \\
Mastitis & 3 to 4.5 & 10 & $587 \pm 120^{\mathrm{f})}$ & ND $^{\mathrm{c})}$ & ND & ND \\
\hline
\end{tabular}

a) Milk quality was categorized according to the results of MBRT.

b) High, normal and low quality of bulk milks were collected from 70 different farms during a four-month period; mastitic milk was individually collected from 10 goats.

c) ND: Not done.

d), e) and f) Means in the same row with a different superscript differ significantly $(P<0.05)$. 
the mean LFC in high quality milk is significantly lower than those of normal and low quality milk $(P<0.05)$. Thus, high quality milk was found to show a low level of LFC in milk and vice versa. Moreover, the mean LFC of mastitic milk was found to be $587 \mu \mathrm{g} / \mathrm{ml}$.

Milk fat, acidity and specific gravity: Milk fat, acidity and specific gravity are also used for setting the price of goat milk in Taiwan. The reference or accepted values for milk fat is more than $3.6 \%$, for milk acidity, it is below $0.18 \%$, and for specific gravity, it is between 1.030 and 1.034 (measured at $\left.15^{\circ} \mathrm{C}\right)$. The alcohol test $(45 \%)$ is also used to monitor the quality of raw milk of dairy goats in Taiwan. When the milk coagulated in the alcohol test, it will not be accepted for sale and thus discarded.

The milk fat, acidity and specific gravity of different levels of MBRT are shown in Table 1. Although the MBRT times for high, normal and low quality milk are different, the mean acidity, milk fat and specific gravity of these three kinds of milk were all within acceptable limit as mentioned above and not significantly different from each other (oneway ANOVA).

Bacteriological examination for milk from udder halves infected by $S$. aureus: The $S$. aureus counts in milk from the control udder halves were zero during the experiment. However, $S$. aureus was isolated from milk taken from the inoculated-udder halves at 24, 48 and $72 \mathrm{hr}$ postinoculation (PI). Thus, one of the udder halves of each goat was successfully infected with the $S$. aureus. The mean $S$. aureus counts increased continuously from the 0 cells $/ \mathrm{m} l(0 \mathrm{hr})$ to about 10,000 cells $/ \mathrm{ml}(72 \mathrm{hr})$ in infected milk.

LFC and SCC in milk from udder halves infected by $S$. aureus: The LFC and SCC in control or S. aureus-infected milk are shown in Fig. 2. The mean SCC in control milk was consistent, ranging from about 3 to $4 \times 10^{5}$ cells $/ \mathrm{m} l$ during the course of the experiment. The mean SCC in $S$. aureus infected milk was found to be elevated at the 24,48 and $72 \mathrm{hr}$ PI. Mean SCC in those milk increased from about $2 \times 10^{5}$ cells $/ \mathrm{ml}(0 \mathrm{hr})$ to $3 \times 10^{6}$ cells $/ \mathrm{ml}(24 \mathrm{hr} \mathrm{PI})$ and then to about $4 \times 10^{6}$ cells $/ \mathrm{ml}$ ( 48 and $72 \mathrm{hr}$ PI). Moreover, the mean SCC was significantly higher in $S$. aureus infected milk than in control at the 48 and $72 \mathrm{hr}(\mathrm{P}<0.05$; student's $t$ test) after the bacteria inoculation.

Mean LFC of the infected milk also increased gradually from $10 \mu \mathrm{g} / \mathrm{ml}(0 \mathrm{hr}$ ) to about $1,000 \mu \mathrm{g} / \mathrm{ml}$ (at $72 \mathrm{hr}$ ). However, the LFC in control milk was consistent and ranged from 10 to $30 \mu \mathrm{g} / \mathrm{m} l$ throughout the experiment. The mean LFC was significantly higher in $S$. aureus infected milk than in the control milk at $72 \mathrm{hr}(P<0.05$; student's $t$ test $)$ after the bacteria inoculation. Thus, SCC was found to increase (at the $24 \mathrm{hr}$ ) earlier than the LFC (at the $48 \mathrm{hr}$ ) in the mastitic milk (Fig. 2).

Relationship between LFC and MBRT or SCC: The relationship between LFC and MBRT time of milk is shown in Fig. 3. For comparison, the reaction time of the MBRT for milk were divided into five categories; 4 to $5 \mathrm{hr}, 5$ to $6 \mathrm{hr}, 6$ to $7 \mathrm{hr}, 7$ to $8 \mathrm{hr}$ and more than $8 \mathrm{hr}$. The LFC in milk was
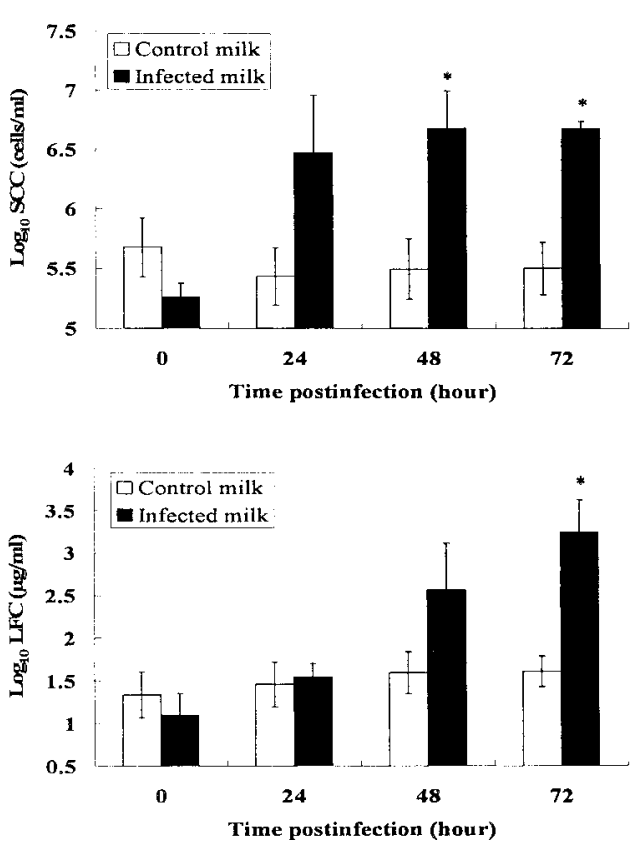

Fig. 2. Lactoferrin concentration (LFC) and somatic cell counts (SCC) in milk at different time intervals from udder halves of three goats. One of the udder halves of each goat was inoculated with $100 \mathrm{cells} / \mathrm{ml}$ of Staphylococcus aureus within $1 \mathrm{hr}$ after collection of control milk. Mean \pm SEM is shown. * Significant difference to control milk $(P<0.05)$.

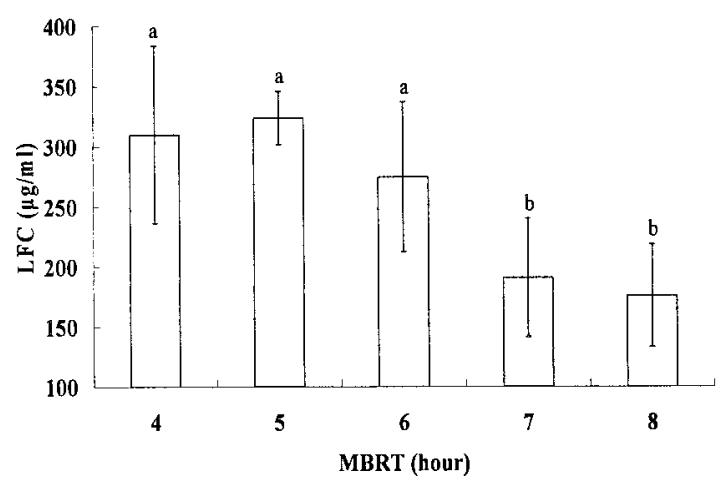

Fig. 3. Lactoferrin concentration (LFC) in milk of different time intervals by methylene blue reduction test (MBRT). Mean \pm standard deviation is shown. ${ }^{\mathrm{a}, \mathrm{b}}$ Different alphabet denotes presence of significant difference $(P<0.01)$.

found to be inversely correlated to the MBRT time. The correlation coefficient between LFC and MBRT time was 0.7 (Pearson correlation test; $P<0.001$ ). The correlation coefficient between LFC and SCC in intramammary challenge test was 0.973 and 0.891 at the 48 and $72 \mathrm{hr}$, respectively (Pearson correlation test; $P<0.05$ ). 


\section{DISCUSSION}

In MBRT, the blue coloration of methylene blue turned colorless after the reducing reaction, and the dye-milk mixture displays the white appearance of milk [26]. The time taken for the reducing reaction to be completed in the MBRT has been demonstrated to be inversely related to the number of bacteria in the milk [6]. Presently, the quality of cow milk is monitored by the SCC or California mastitis test (CMT) [15]. On the other hand, milk from commercial dairy goat herds in southern Taiwan which are enrolled in a registration program was graded to be of high, normal and low quality by the MBRT time. Low quality bulk milk as measured by the MBRT is not accepted for sale.

Our results indicated that the LFC in naturally or experimentally infected mastitic milk was significantly higher than that in normal milk. Moreover, the LFC in high quality milk as categorized by MBRT time was found to be significantly lower than in normal or low quality milk. These findings suggest that the milk LFC has the potential to be used as an index for milk quality or intramammary infection in dairy goats. Despite previous studies suggesting that milk SCC does not contribute to the diagnosis of mastitis in dairy goats [7, 20,35], we observed elevated milk SCC in the milk from the udder halves of the three intramammary-inoculated goats. Thus, we suggest that the SCC might be helpful in the diagnosis of mastitis in goats. However, no SCC criterion has been suggested for the diagnosis of mastitis in goats to date because of the high SCC even in normal lactational goat milk. The milk SCC in normal lactating goats has been reported to range from $1 \times 10^{6}$ to $5 \times 10^{6}$ cells $/ \mathrm{m} l[9,10]$. Thus, although the milk SCC would increase during mastitis in goats, it would be difficult to differentiate between the mastitic milk and that of a particular normal milk with a high level of SCC. Taken together, we suggest that a sudden elevation of milk SCC may be used with other mastitis indices such as the MBRT, LFC or CMT to improve the diagnosis of mastitis in goats.

Several factors that may affect the milk LFC have been reported in dairy cows. Kawai et al. [18] reported that the LFC in milk from quarters infected with Mycoplasma bovis or $S$. aureus was significantly higher than those infected with coagulase-negative Staphylococci (CNS) in clinical mastitis of cows. They also reported that the LFC in clinical mastitic milk was significantly higher than that in subclinical mastitis and normal milk. However, in our study, the mean LFC in subclinical mastitic milk could be as high as $1,000 \mu \mathrm{g} / \mathrm{ml}$, while that of clinical mastitis was about 587 $\mu \mathrm{g} / \mathrm{m} l$. The low LFC in clinical mastitic milk might be due to the samples belonging to that of the chronic mastitic milk. As the acute inflammation of the udder halves progressed to the chronic stage, the decline in milk SCC may subsequently result in the decrease release of LFC into the milk. Moreover, Hagiwara et al. [12] also reported the mean milk LFC in subclinical mastitic cows infected with major pathogens such as $S$. aureus and other Streptococci species were significantly higher than those infected with the minor pathogens such as the CNS and Corynebacterium bovis. Although we did not study the relationship between the presence of pathogens in milk and milk LFC, we postulated that the elevated milk LFC in goats could be attributed to the presence of pathogens in the milk because the pathogenicity of bacteria species is often associated with induction of local inflammation. Hagiwara et al. [12] showed that the milk LFC of cows aged five years was lower than those aged two or three years. They also reported that the milk LFC of cows in late lactational period tended to be higher than those in peak or middle lactational period. They suggested that milk LFC tend to increase in proportion to increase in the number of SCC in normal lactating and subclinical mastitic cows. Although the relationship between milk LFC and age of the cow, stage of lactation as well as milk SCC had been implicated, we consider that these observations need to be evaluated extensively because the milk LFC in the various milk groups in that study were statistically same in most of the cases. On the other hand, in our study, the milk LFC correlated significantly with the milk SCC in the subclinical mastitic goats. Our finding of the elevated SCC could be explained by the massive and rapid accumulation of inflammatory cells such as neutrophils in milk during mastitis which in turn releases their lactoferrin into the local microenvironment. However, the relationship between milk LFC and SCC during normal lactational period of healthy goats should also be elucidated. Schanbacher et al. [29] reported that the concentration of the milk lactoferrin and its messenger RNA increased during the development of the mammary gland, colostrum formation and involution of the mammary gland in cow but decreased during lactation. Since the epithelial cells in the mammary gland releases relatively low level of lactoferrin into the milk, we speculate that the level of SCC in milk during the normal lactation may be relative to the milk LFC both in goat and cow. Therefore, the age of the lactating animals, stage of lactation, milk SCC or the presence of pathogens in milk may affect the milk LFC, but further studies are needed in dairy goat herds.

In this study, we reported the value of milk LFC in large goat herds for the first time. The mean LFC of high quality of bulk milk from goats obtained from 44 commercial farms in normal lactation was found to be about $167 \mu \mathrm{g} / \mathrm{ml}$ (ranging from 69 to $265 \mu \mathrm{g} / \mathrm{ml}$ ). Masson and Heremans [22] found the LFC in pooled milk from several goats (Capra ibex) to be 20 to $200 \mu \mathrm{g} / \mathrm{m} l$ by radial immunodiffusion. Our LFC values concurred with their findings. Thus, the LFC of this kind of milk (high quality bulk milk) can be considered as an index for the normal lactating goats. However, the LFC of the individual milk samples from the individual goats need to be determined so as to clarify the variation of LFC in goat's milk for establishing a suitable LFC threshold for grading the milk quality. In addition, the milk LFC during normal lactational period in human, cow and swine had been reported to be 1,000 to $2,000,20$ to 200 and $30 \mu \mathrm{g} / \mathrm{ml}$, respectively $[11,16,19,28]$. Therefore, the milk LFC in goat during normal lactation is similar to that in cow. 
Dionysius et al. [8] reported that a concentration of 200 $\mu \mathrm{g} / \mathrm{m} l$ of apo-lactoferrin could be used to distinguish the target $E$. coli strain as either sensitive or resistant to inhibition. Although the milk LFC in normal lactating cows or goats is low (about 20 to $300 \mu \mathrm{g} / \mathrm{m} l$ ), it could increase to a high level during clinical or subclinical mastitis in cows and goats. The LFC in milk from cows infected by various pathogens in clinical or subclinical mastitis was observed to be more than $500 \mu \mathrm{g} / \mathrm{m} l$ except for those infected with $C$. bovis [12, 18]. Thus, the elevation of milk LFC during mastitis would be effective in inhibiting the growth of bacteria in the milk. Similarly, we also observed that the milk LFC in subclinical mastitis of goats increased from $10 \mu \mathrm{g} / \mathrm{ml}(0 \mathrm{hr})$ to about $1,000 \mu \mathrm{g} / \mathrm{ml}$ (at $72 \mathrm{hr} \mathrm{PI}$ ). On the contrary, the relatively low milk LFC during normal lactational period showed that it might not be responsible for the protective functions of the mammary glands but might be involved with other physiological functions such as growth factor-like activity.

In conclusion, the milk LFC may be useful for determining the infection status of udder halves in dairy goats, their values in individual dairy goats should be further studied to elucidate the factors affecting the level of lactoferrin in milk.

ACKNOWLEDGMENTS. We thank Dr. H. K. Ooi for the revision of manuscript, the Taiwan Jia-Nan goat milk marketing cooperation for providing the milk samples, and $\mathrm{Mr}$. C.-B. Yang and Dr. J.-T. Hsu for their help with the SCC. This work was supported by a grant 92AS-3.1.3-AD-U1 from Council of Agriculture, Executive Yuan (Taiwan).

\section{REFERENCES}

1. Anderson, M. and Andrews, A. T. 1977. Progressive changes in individual milk protein concentrations associated with high somatic cell counts. J. Dairy Res. 44: 223-235.

2. Autiero, M., Sansone, G. and Abrescia, P. 1991. Relative ratios of lactoferrin, albumin, and acid phosphatase seminal levels as sperm quality markers in fertile and infertile men. J. Androl. 12: 191-200.

3. Brock, J. H. 2002.The physiology of lactoferrin. Biochem. Cell Biol. 80: 1-6.

4. Bullen, J. J., Rogers, H. J. and Leigh, L. 1972. Iron-binding proteins in milk and resistance to Escherichia coli infection in infants. Br. Med. J. 1: 69-75.

5. Chinese national standard. 1996. Methods of Test for Milk and Milk Products: General Rules. Bureau of Standards, Metrology and Inspection. CNS 3440, Taiwan.

6. Dabbah, R., Tatini, S. R. and Olson, J. C. 1967. Comparison of methods for grading milk intended for manufacturing purposes. J. Milk Food Techol. 30: 71-76.

7. David, J. W., Steward, K. N. and Sears, P. M. 1995. Effects of stage of lactation, production, parity and season on somatic cell counts in infected and uninfected dairy goats. Small Rumin. Res. 16: 165-169.

8. Dionysius, D. A., Grieve, P. A. and Milne, J. M. 1993. Forms of lactoferrin: their antibacterial effect on enterotoxigenic Escherichia coli. J. Dairy Sci. 76: 2597-2600.

9. Droke, E. A., Paape, M. J. and Di Carlo, A. L. 1993. Prevalence of high somatic cell counts in bulk tank goat milk. $J$.
Dairy Sci. 76: 1035-1039.

10. Dulin, A. M., Paape, M. J., Schultz, W. D. and Weinland, B. T. 1983. Effect of parity, stage of lactation, and intramammary infection on concentration of somatic cells and cytoplasmic particles in goat milk. J. Dairy Sci. 66: 2426-2433.

11. Elliot, J. I., Senft, B., Erhardt, G. and Fraser, D. 1984. Isolation of lactoferrin and its concentration in sows' colostrum and milk during a 21-day lactation. J. Anim. Sci. 59: 1080-1084.

12. Hagiwara, S., Kawai, K., Anri, A. and Nagahata, H. 2003. Lactoferrin concentration in milk from normal and subclinical mastitic cows. J. Vet. Med. Sci. 65: 319-323.

13. Hansen, N. E., Malmquist, J. and Thorell, J. 1975. Plasma myeloperoxidase and lactoferrin measured by radioimmunoassay: relations to neutrophil kinetics. Acta Medica. Scandinavica. 198: 437-443.

14. Harlow, E. and Lane, D. 1988. pp. 92-119. In: Antibodies: Laboratory Manual (Harlow, E. and Lane, D. eds.), Cold Spring Harbor, New York.

15. Harmon, R. J. 1994. Physiology of mastitis and factors affecting somatic cell counts. J. Dairy Sci. 77: 2103-2112.

16. Harmon, R. J., Schanbacher, F. L., Ferguson, L. C. and Smith, K. L. 1975. Concentration of lactoferrin in milk of normal lactating cows and changes occurring during mastitis. Am. J. Vet. Res. 36: 1001-1007.

17. He, J. and Furmanski, P. 1995. Sequence specificity and transcriptional activation in the binding of lactoferrin to DNA. Nature (Lond.) 373: 721-724.

18. Kawai, K., Hagiwara, S., Anri, A. and Nagahata, H. 1999. Lactoferrin concentration in milk of bovine clinical mastitis. Vet. Res. Commun. 23: 391-398.

19. Lonnerdal, B., Forsum, E., Gebre-Medhin, M. and Hambraeus, L. 1976. Breast milk composition in Ethiopian and Swedish mothers. II. Lactose, nitrogen, and protein contents. Am. J. Clin. Nutr. 29: 1134-1141.

20. Manser, P. A. 1986. Prevalence, causes and laboratory diagnosis of subclinical mastitis in the goat. Vet. Rec. 118: 552-554.

21. Mao, F. C. and Bremel, R. D. 1995. Prediction of milk yields from serum $\beta$-lactoglobulin concentrations in pregnant heifers. J. Dairy Sci. 78: 291-295.

22. Masson, P. L. and Heremans, J. F. 1971. Lactoferrin in milk from different species. Comp. Biochem. Physiol. B 39: 119129.

23. Masson, P. L., Heremans, J. F. and Schonne, E. 1969. Lactoferrin, an iron-binding protein in neutrophilic leukocytes. J. Exp. Med. 130: 643-658.

24. Nam, M. S., Shimazaki, K., Kumara, H., Lee, K. K. and Yu, D. Y. 1999. Characterization of Korean native goat lactoferrin. $B$ Comp. Biochem. 123: 201-208.

25. Rein, M. F., Shih, L. M., Miller, J. R. and Guerrant, R. L.1996. Use of a lactoferrin assay in the differential diagnosis of female genital tract infections and implications for the pathophysiology of bacterial vaginosis. Sex. Transm. Dis. 23: 517-521.

26. Edmondson, J. E., Golden, R. and Wedle, D. B. 1985. Reduction methods. pp. 259-264. In: Standard Methods for the Examination of Dairy Products, 15th ed. (Richardson, G. H. ed.), Am. Publ. Health Assoc., Inc., Washington, D.C.

27. SAS® User's guide. 1996. Statistics, Version 6.12 Edition. SAS Inst., Inc., Cary, NC.

28. Schanbacher, F. L. and Smith, K. L. 1975. Formation and role of unusual whey proteins and enzymes: Relation to mammary function. J. Dairy Sci. 58: 1048-1062.

29. Schanbacher, F. L., Talhouk, R. S. and Murray, F. A. 1997. Biology and origin of bioactive peptides in milk. Livest. Prod. 
Sci. 50: 105-123.

30. Semba, R. D., Kumwenda, N., Taha, T. E., Hoover, D. R., Lan, Y., Eisinger, W., Mitmavalye, L., Broadhead, R., Miotti, P. G., Van Der Hoeven, L. and Chiphangwi, J. D. 1999. Mastitis and immunological factors in breast milk of lactating women in Malawi. Clini. Diagn. Lab. Immunol. 6: 671-674.

31. Tomita, M., Wakabayashi, H., Yamauchi, K., Teraguchi, S. and Hayasawa, H. 2002. Bovine lactoferrin and lactoferricin derived from milk: production and applications. Biochem. Cell Biol. 80: 109-112.

32. Vandeputte-Van, M. G., Burvenich, C., Roets, E., MassartLeen, A. M., Heyneman, R., Kremer, W. D. and Brand, A.
1993. Classification of newly calved cows into moderate and severe responders to experimentally induced Escherichia coli mastitis. J. Dairy Res. 60: 19-29.

33. Vorland, L. H. 1999. Lactoferrin: a multifunctional glycoprotein. Acta Pathol. Microbiol. Immunol. Scand. 107: 971-981.

34. Wright, D. G. and Gallin, J. I. 1979. Secretory responses of human neutrophils: exocytosis of specific (secondary) granules by human neutrophils during adherence in vitro and during exudation in vivo. J. Immunol. 123: 285-294.

35. Zeng, S. S. and Escobar, E. N. 1995. Effect of parity and milk production on somatic cell count, standard plate count and composition of goat milk. Small Rumin. Res. 17: 269-274. 